\title{
Numerical Research on Unsteady aerodynamics of a WIG Airfoil Flying over Wavy Water Surface
}

\author{
P. Q. Liu, X. G. Qin*, Q. L. Qu
}

School of Aeronautics Science and Technology, Beijing University of Aeronautics and Astronautics, Beijing 100083, China

Email: BY0405118@163.com

\begin{abstract}
Aerodynamic characteristics of an airfoil, NACA 2410, flying over wavy water surface is investigated numerically in this paper.

The aerodynamic characteristics of the airfoil are affected by the unsteady near wavy ground effect. The air upon the wavy water surface has a corresponding velocity affected by the wave. The water surface has a deformation by the high pressure below the airfoil. Since the experiment to research the acrodynamic characteristics of WIG airfoil is very difficult, numerical method is used in this paper. The commercially available CFD code. FLUENT, was used as the numerical model.

The airfoil cruises on wavy water surface with Mach number $M a=0.35$ and Reynolds number $R e=$ $8.96 \times 10^{7}$, based on the airfoil chord length. Wavelength varies from $40 \mathrm{~m}$ to $150 \mathrm{~m}$, and wave amplitude varies from $0.6 \mathrm{~m}$ to $2 \mathrm{~m}$. The air affected by the wavy water surface will have a corresponding velocity that can be expressed from the theory of two superposed fluids.

The finite volume method is used to solve Reynolds-Averaged Navier-Stokes equations, using Realizable $k-\varepsilon$ model. The SIMPLE algorithm is used in all computations. The momentum equations are discretized using second order upwind scheme options. The free surface of the water and the air is handled by VOF (Volume of Fluid) method, using a Geometric Reconstruction Scheme. The boundary conditions, that contain the position of the free surface of air and the water, the velocity of the water particles and the velocity of the air particles upon the wave, are given by UDFUser-defined Functions.

The simulated wave is coincident with regular cosine law well. The deformation of the water under the airfoil caused by the high pressure is very small. The deformation develops more downstream behind the airfoil, but can not affect the aerodynamic characteristics of the airfoil obviously.

When the airfoil is moving on the sinusoidal water wave surface, the aerodynamic characteristics of the airfoil, $\mathrm{Cl}, \mathrm{Cd}, \mathrm{Cm}$ and position of center of pressure for the airfoil, are periodical. But they do not vary in compliance with the sinusoidal law.

The angle of attack and the flight height is fixed at 6 degree and $h / c=0.20$ respectively, the rank of the wave is changed. First, the wave amplitude is fixed at $0.5 \mathrm{~m}$, five wave lengths are considered, $\lambda=40 \mathrm{~m}, 50 \mathrm{~m}, 80 \mathrm{~m}, 110 \mathrm{~m}, 150 \mathrm{~m}$. The lift coefficient decreases from the wave length varying from $40 \mathrm{~m}$ to $110 \mathrm{~m}$, and then grows up. The effect of wave is obvious with short wavelength. Second, the wave length is fixed at $50 \mathrm{~m}$, three wave amplitudes vary from $0.5 \mathrm{~m}$ to $1 \mathrm{~m}$. The fluctuation of acrodynamic characteristics increases when the wave amplitude increases. With the increase of the amplitude, the effect of the wave is more obvious, and the inconsistent trend from sinusoidal law is essential.
\end{abstract}

\section{REFERENCES}

1. Im Y H, Chang K S. Unsteady aerodynamics of a WIG airfoil flying over a wavy wall. AIAA 2000-0657

2. Sheng Q H, Wu D M, Zhang L. Aerodynamic forces acting on an albatross flying above sea waves. Applied Mathematics and Mechanics, 2005(9): 1122-1129

3. Barber T, Leonardi E. Free surface deformation caused a wing in ground effect over water. In: Proc.International Workshop. Wise up to Ekranoplan GEMS.The University of New South Wales,Sdney,Austrialia,15-16,June,1998; 90-101 